\title{
Expanding the Chemical Space of Aryloxy- naphthoquinones as Potential Anti-chagasic Agents: Synthesis and Trypanosomicidal Activity
}

Nohemí A. Becerra

Universidad Autónoma de Nuevo León: Universidad Autonoma de Nuevo Leon

Christian Espinosa-Bustos

Pontifical Catholic University of Chile: Pontificia Universidad Catolica de Chile

Karina Vázquez

Universidad Autónoma de Nuevo León: Universidad Autonoma de Nuevo Leon

Gildardo Rivera

Instituto Politécnico Nacional: Instituto Politecnico Nacional

Margot Paulino

Universidad de la República Uruguay: Universidad de la Republica Uruguay

Jorge Cantero

Universidad de la República Uruguay: Universidad de la Republica Uruguay

Benjamín Nogueda

Instituto Politécnico Nacional: Instituto Politecnico Nacional

Fabiola Chacón-Vargas

Universidad Autonoma de Chihuahua

Uziel Castillo-Velazquez

Universidad Autónoma de Nuevo León: Universidad Autonoma de Nuevo Leon

Ana F. Elizondo Rodríguez

Universidad Autónoma de Nuevo León: Universidad Autonoma de Nuevo Leon

\section{Sofía Toledo}

Pontificia Universidad Católica de Chile: Pontificia Universidad Catolica de Chile

\section{Adriana Moreno-Rodríguez}

Universidad Autónoma Benito Juárez de Oaxaca: Universidad Autonoma Benito Juarez de Oaxaca

\section{Mario Aranda}

Pontifical Catholic University of Chile: Pontificia Universidad Catolica de Chile

cristian osvaldo salas ( $\nabla$ cosalas@uc.cl)

Pontificia Universidad Catolica de Chile https://orcid.org/0000-0001-7620-2459 
Keywords: Trypanosoma cruzi, trypomastigote, epimastigote, aryloxy-naphthoquinones, pharmacophoric analysis, ADME properties

Posted Date: August 4th, 2021

DOI: https://doi.org/10.21203/rs.3.rs-756093/v1

License: (c) (i) This work is licensed under a Creative Commons Attribution 4.0 International License. Read Full License 


\section{Abstract}

In continuation our effort to research the chemical space of aryloxy-naphthoquinones as potential antiChagas agents, we synthesized nine derivatives and these compounds were evaluated in vitro against the epimastigote and trypomastigote forms of Mexican strains of Trypanosoma cruzi (T. cruzi). Most of these derivatives are highly active against epimastigote forms $\left(\mathrm{IC}_{50}<1.0 \mu \mathrm{M}\right)$ compared to the reference drug benznidazole (Bzn). Then these were evaluated on trypomastigotes, which is showing better potency results than Bzn for compounds $\mathbf{3 b}$ and $\mathbf{3 g}$. In addition, the cytotoxicity of these compounds was determined on the murine macrophage cell line J774. $\mathbf{3 b}$ and $\mathbf{3 i}$ were the most selective compounds against NINOA trypomastigote and INC-5 epimastigote forms, respectively. Further these compounds also have good oral bioavailability according to theoretical predictions. Finally, we were able to determine optimal substitution patterns using pharmacophoric models. All these results are provided very useful structural information to continue our designing of naphthoquinone derivatives against $T$. cruzi.

\section{Introduction}

Chagas disease or American trypanosomiasis is one of the 20 "Neglected Tropical Diseases" (NTD) (WHO, 2020). The disease is caused by Trypanosoma cruzi (T. cruzi), a protozoan parasite endemic in Latin America. It affects approximately 7 million people and causes more than 10000 deaths a year [1]. There are two drugs approved for the treatment of this disease, benznidazole (Bzn) and nifurtimox (Nfx) [2]. Both are effective in the early stages of the disease (acute stage), but their efficacy is limited in advanced stages (chronic stage). These drugs also present serious adverse effects and require long-term therapy leading to treatment suspension $[3,4]$. Considering the above and the fact the pharmaceutical industry does not invest in research for NTDs, it is great importance to find new alternatives for the treatment of trypanosomiasis. For this reason, many academic research groups are searching for new trypanosomicidal therapeutic alternatives through the design and synthesis of small molecules $[5,6]$.

Compounds derived from a naphthoquinone scaffold appear to be an interesting alternative for the Chagas disease pharmacotherapy. Lapachol I and a-lapachone II (Fig. 1) are important naphthoquinone derivatives in nature with trypanosomicidal activity $[7,8]$. Considering this background, a library of 2aryloxy-1,4-naphthoquinone compounds were synthesized by Bolognesi et al. 2-phenoxy-1,4naphthoquinone III (Fig. 1) was the most prominent derivative in this series, with an $\mathrm{IC}_{50}$ of $1.70 \mu \mathrm{M}$ against $T$. cruzi amastigotes [9].

In recent years, our research group has focused on the search for new anti- $T$. cruzi agents containing the structure of the aryloxy-quinone scaffold. Our first approach was through the synthesis of aryloxyindolequinone derivatives and their evaluation against $T$. cruzi epimastigotes culture. Of these, 6phenoxyindolequinone derivative IV (Fig. 1) showed excellent inhibitory activity in the nanomolar range against $Y$ strain epimastigote $\left(\mathrm{IC}_{50}=20 \mathrm{nM}\right)[10]$. 
In a subsequent article, our group reported the synthesis and trypanosomicidal activity of 2-aryloxynaphthoquinones, 7-aryloxyquinolinquinones and 6-aryloxy-furonaphthoquinones derivatives [11]. In this work compound 2-(3-nitrophenyloxy)-naphthoquinone $\mathbf{V}$ (Fig. 1) showed an $\mathrm{IC}_{50}=20 \mathrm{nM}$ and a selectivity index (SI) of 625 against $\mathbf{J 7 7 4}$ murine macrophage cells, which showed low toxicity against nonneoplastic cells. In our last report on aryloxy-naphthoquinones with trypanosomicidal activity, we obtained good results against epimastigote cultures with an $\mathrm{IC}_{50}=230 \mathrm{nM}$ for 2-(4-methyl-3nitrophenoxy)-naphthoquinone VI (Fig. 1) [12].

From these results, we observed the presence of an aryloxy group attached to the naphthoquinone core is important for anti-T. cruzi activity. Furthermore, we have noticed the addition of a nitro or a methyl group on the aryloxy moiety gives rise to compounds with equal or better trypanosomicidal activity. It remarked that Nfx and Bzn, drugs have been used in the chemotherapy of Chagas disease, have a nitro group in their structure. Interestingly, in 2017 the FDA has approved Bzn as pharmacological treatment for the Chagas disease [13]. Therefore, considering the aforementioned, in this work, we carried out the synthesis of new naphthoquinones (Fig. 1), which was functionalized according to four criteria, to evaluate the effect of these modifications on the trypanosomicidal effect on epimastigote and tripomastigote forms from Mexican strains of $T$. cruzi.

These modifications were: (a) the substitution of the hydrogen atom on C-3 by bromine or chlorine because it has been reported that this change modulates the trypanosomicidal activity on Tulahuén, NINOA, INC-5 and Y strains [14]. In the aryloxy moiety: (b) the substitutions of a nitro group in the aryloxy moiety at meta or para position; (c) as shown in $\mathrm{Vl}$, a methyl group at para position and meta position; (d) a substitution at para position by chlorine atom. With these new derivatives, our group expanded the library of compounds with trypanosomicidal activity and contributed to the chemical space of naphthoquinones with anti-Chagasic activity.

\section{Experimental Section}

\section{General}

Melting points were determined on a Kofler Thermogerate apparatus and were uncorrected. IR spectra were recorded on a JASCO FT/IR-400 spectrophotometer. NMR spectra were recorded, unless otherwise specified, on a Bruker AM-400 instrument using deuterochloroform $\left(\mathrm{CDCl}_{3}\right)$ or deuterodimethylsulfoxide (DMSO- $\delta$ ) solutions containing tetramethylsilane as an internal standard. Samples were analysed using an Advion (Itaca, NY, USA) Expression-L mass spectrometer equipped with an electrospray ionization source $(E S I)$. Sample were directly injected $(5 \mu \mathrm{L})$ using LC-grade methanol as mobile phase. Mass spectrometry analysis was carried out using the following settings: ESI (-) voltage of $2.5 \mathrm{kV}$, nebulizer gas $\left(\mathrm{N}_{2}\right)$ flow: $3.0 \mathrm{~L}$ min-1, drying gas flow: $10 \mathrm{~L}$ min-1, desolvation line temperature $200^{\circ} \mathrm{C}$ and heat block temperature $250^{\circ} \mathrm{C}$. Analytes were evaluated in Full Scan mode (m/z) 100-1500. Data was acquired by means of Advion Mass Express and processed applying Data Express Software. Thin layer chromatography (TLC) was performed using Merck GF-254 type 60 silica gel. Column chromatography 
was carried out using Merck type 9385 silica gel. The purity of the compounds was determined by TLC. All the spectra of aryloxy-quinones synthesized are shown in the Supporting information.

\section{General procedure for the synthesis of aryloxy-naphthoquinones.}

In a reaction flask, the suitable phenol $(1.1 \mathrm{mmol})$ and $\mathrm{K}_{2} \mathrm{CO}_{3}(2 \mathrm{mmol})$ were suspended in DMF $(5 \mathrm{~mL})$. The mixture was stirred for $10 \mathrm{~min}$, and then, the corresponding naphthoquinone (1 mmol) was added. Later, the reaction mixture was stirred for $2-3 \mathrm{~h}$ at room temperature. The solvent was then removed under vacuum, and the solid residue was purified by column chromatography on silica gel and using dichloromethane as the mobile phase.

2-(4-Methyl-3-nitrophenoxy)naphthalene-1,4-dione 3a. Yellow solid, yield $63 \%$, mp $163-165^{\circ} \mathrm{C} .{ }^{1} \mathrm{H}$ NMR $\left(400 \mathrm{MHz}, \mathrm{CDCl}_{3}\right) \delta 8.21-8.15(\mathrm{~m}, 1 \mathrm{H}), 8.10-8.03(\mathrm{~m}, 1 \mathrm{H}), 7.81(\mathrm{~d}, J=2.5 \mathrm{~Hz}, 1 \mathrm{H}), 7.79-7.75(\mathrm{~m}, 2 \mathrm{H})$, $7.46(\mathrm{~d}, J=8.4 \mathrm{~Hz}, 1 \mathrm{H}), 7.32(\mathrm{dd}, J=8.4,2.5 \mathrm{~Hz}, 1 \mathrm{H}), 6.01(\mathrm{~s}, 1 \mathrm{H}), 2.64(\mathrm{~s}, 3 \mathrm{H}) .{ }^{13} \mathrm{C}$ NMR $(101 \mathrm{MHz}, \mathrm{CDCl} 3)$ $\delta 184.48,179.34,159.48,151.07,149.73,134.67,134.63,133.81,131.99,131.82,130.96,126.90,126.38$, $125.71,117.51,114.42,20.12$. MS (ESI) for $\left(\mathrm{C}_{17} \mathrm{H}_{11} \mathrm{NO}_{5}[\mathrm{M}-]\right)$ : 309.3. Found 309.0.

2-Chloro-3-(4-methyl-3-nitrophenoxy)naphthalene-1,4-dione 3b. Yellow solid, yield $23 \%$, mp 201-203 ${ }^{\circ} \mathrm{C}$.

${ }^{1} \mathrm{H}$ NMR $\left(400 \mathrm{MHz}, \mathrm{CDCl}_{3}\right) \delta 8.22(\mathrm{~d}, J=7.0 \mathrm{~Hz}, 1 \mathrm{H}), 8.05(\mathrm{~d}, J=6.8 \mathrm{~Hz}, 1 \mathrm{H}), 7.85-7.74(\mathrm{~m}, 2 \mathrm{H}), 7.61(\mathrm{~d}, J$ $=1.6 \mathrm{~Hz}, 1 \mathrm{H}), 7.33(\mathrm{~d}, J=8.4 \mathrm{~Hz}, 1 \mathrm{H}), 7.24-7.17(\mathrm{~m}, 1 \mathrm{H}), 2.58(\mathrm{~s}, 3 \mathrm{H}) .{ }^{13} \mathrm{C} \mathrm{NMR}\left(101 \mathrm{MHz}, \mathrm{CDCl}_{3}\right) \delta$ 178.02, 177.62, 154.49, 152.74, 149.27, 134.85, 134.67, 134.47, 134.00, 131.16, 130.43, 129.37, 127.58, 127.31, 121.66, 112.82, 20.02. MS (ESI) for $\left(\mathrm{C}_{17} \mathrm{H}_{10} \mathrm{CINO}_{5}[\mathrm{M}-]\right)$ : 343.0. Found 343.0.

2-Bromo-3-(4-methyl-3-nitrophenoxy)naphthalene-1,4-dione 3c. Yellow solid, yield $24 \%$, mp 188-190 $\mathrm{C}$. ${ }^{1} \mathrm{H}$ NMR $(400 \mathrm{MHz}, \mathrm{CDCl} 3)$ 8 8.16-8.08 (m, 1H), $7.95(\mathrm{dd}, J=7.2,1.7 \mathrm{~Hz}, 1 \mathrm{H}), 7.76-7.64(\mathrm{~m}, 2 \mathrm{H}), 7.52(\mathrm{~d}$, $J=2.6 \mathrm{~Hz}, 1 \mathrm{H}), 7.24(\mathrm{~d}, J=8.5 \mathrm{~Hz}, 1 \mathrm{H}), 7.13(\mathrm{dd}, J=8.4,2.6 \mathrm{~Hz}, 1 \mathrm{H}), 2.49(\mathrm{~s}, 3 \mathrm{H}) .{ }^{13} \mathrm{C}$ NMR $(101 \mathrm{MHz}$, $\mathrm{CDCl}_{3}$ ) $\delta 178.07,177.09,155.21,154.37,149.28,134.81,134.59,134.01,131.06,130.44,129.33,128.61$, $127.84,127.37,121.64,112.81,20.02$. MS (ESI) for $\left(\mathrm{C}_{17} \mathrm{H}_{10} \mathrm{BrNO}_{5}[\mathrm{M}-]\right)$ : 386.9 . Found 387.0

2-(4-Chloro-3-nitrophenoxy)naphthalene-1,4-dione 3d. Yellow solid, yield $54 \%, \mathrm{mp} 164-165^{\circ} \mathrm{C} .{ }^{1} \mathrm{H}$ NMR $\left(400 \mathrm{MHz}, \mathrm{CDCl}_{3}\right) \delta 8.18-8.14(\mathrm{~m}, 1 \mathrm{H}), 8.09-8.05(\mathrm{~m}, 1 \mathrm{H}), 7.83-7.74(\mathrm{~m}, 2 \mathrm{H}), 7.72(\mathrm{~d}, J=2.8 \mathrm{~Hz}, 1 \mathrm{H})$, $7.65(\mathrm{~d}, J=8.8 \mathrm{~Hz}, 1 \mathrm{H}), 7.35(\mathrm{dd}, J=8.8,2.8 \mathrm{~Hz}, 1 \mathrm{H}), 6.11(\mathrm{~s}, 1 \mathrm{H}) .{ }^{13} \mathrm{C} \mathrm{NMR}\left(101 \mathrm{MHz}, \mathrm{CDCl}_{3}\right) \delta 184.25$, 179.06, 158.73, 151.80, 148.51, 134.80, 133.97, 133.66, 131.75, 130.88, 126.95, 126.48, 125.68, 124.71, 118.27, 115.61. MS (ESI) for $\left(\mathrm{C}_{16} \mathrm{H}_{8} \mathrm{CINO}_{5}[\mathrm{M}-]\right): 329.0$. Found 328.9.

2-Chloro-3-(4-chloro-3-nitrophenoxy)naphthalene-1,4-dione 3e. Yellow solid, yield $43 \%$, mp $199-201^{\circ} \mathrm{C} .{ }^{1} \mathrm{H}$ NMR (400 MHz, DMSO) $\delta 8.14$ (dd, J = 7.3, 1.4 Hz, 1H), 8.09 (d, J=2.9 Hz, 1H), 8.02 (dd, J= 7.1, $1.7 \mathrm{~Hz}$, $1 \mathrm{H}), 7.99-7.92(\mathrm{~m}, 2 \mathrm{H}), 7.80(\mathrm{~d}, J=8.9 \mathrm{~Hz}, 1 \mathrm{H}), 7.67$ (dd, $J=8.9,3.0 \mathrm{~Hz}, 1 \mathrm{H}) .{ }^{13} \mathrm{C} N M R(101 \mathrm{MHz}, \mathrm{DMSO})$ $\delta 178.47,177.95,155.51,151.95,148.86,135.15,135.01,134.85,133.13,131.94,131.10,127.14,127.00$, 122.24, 119.30, 113.43. MS (ESI) for $\left(\mathrm{C}_{16} \mathrm{H}_{7} \mathrm{Cl}_{2} \mathrm{NO}_{5}[\mathrm{M}-]\right)$ : 362.9. Found 363.0. 
2-Bromo-3-(4-chloro-3-nitrophenoxy)naphthalene-1,4-dione 3f. Yellow solid, yield $67 \%$, mp $196-198^{\circ} \mathrm{C} .{ }^{1} \mathrm{H}$ $\operatorname{NMR}(400 \mathrm{MHz}, \mathrm{DMSO}) \delta 8.18-8.11(\mathrm{~m}, 1 \mathrm{H}), 8.08(\mathrm{~d}, J=2.9 \mathrm{~Hz}, 1 \mathrm{H}), 8.06-7.98(\mathrm{~m}, 1 \mathrm{H}), 7.97-7.87(\mathrm{~m}$, 2H), $7.79(\mathrm{~d}, J=8.9 \mathrm{~Hz}, 1 \mathrm{H}), 7.66(\mathrm{dd}, J=8.9,2.9 \mathrm{~Hz}, 1 \mathrm{H}) .{ }^{13} \mathrm{C}$ NMR $(101 \mathrm{MHz}, \mathrm{DMSO}) \delta 178.73,177.47$, 155.39, 154.40, 148.90, 135.08, 134.93, 133.11, 131.83, 131.13, 129.70, 127.38, 127.07, 122.19, 119.17, 113.37. $\mathrm{MS}(\mathrm{ESI})$ for $\left(\mathrm{C}_{16} \mathrm{H}_{7} \mathrm{BrClNO}_{5}[\mathrm{M}-]\right)$ : 408.6. Found 409.0.

2-Chloro-3-(4-nitrophenoxy)naphthalene-1,4-dione 3g. Yellow solid, yield $61 \%$ mp $169-170^{\circ} \mathrm{C} .{ }^{1} \mathrm{H}$ NMR

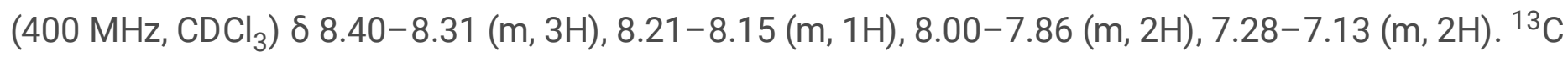
$\operatorname{NMR}\left(101 \mathrm{MHz}, \mathrm{CDCl}_{3}\right) \delta 177.86,177.28,160.65,152.42,143.89,134.98,134.81,131.14,130.33,127.68$, 127.38, 126.04, 116.77. MS (ESI) for $\left(\mathrm{C}_{16} \mathrm{H}_{8} \mathrm{CINO}_{5}[\mathrm{M}-]\right)$ : 329.0. Found 328.9.

2-Chloro-3-(3-methyl-4-nitrophenoxy)naphthalene-1,4-dione 3h. Yellow solid, yield $37 \%$, mp $170-171^{\circ} \mathrm{C}$.

${ }^{1} \mathrm{H}$ NMR $(400 \mathrm{MHz}, \mathrm{DMSO}) \delta 8.19-8.10(\mathrm{~m}, 1 \mathrm{H}), 8.06(\mathrm{~d}, J=9.0 \mathrm{~Hz}, 1 \mathrm{H}), 8.01(\mathrm{dd}, J=7.1,1.5 \mathrm{~Hz}, 1 \mathrm{H})$, $7.98-7.87(\mathrm{~m}, 2 \mathrm{H}), 7.38(\mathrm{~d}, J=2.5 \mathrm{~Hz}, 1 \mathrm{H}), 7.31(\mathrm{dd}, J=9.0,2.7 \mathrm{~Hz}, 1 \mathrm{H}), 2.51(\mathrm{~s}, 2 \mathrm{H}) .{ }^{13} \mathrm{C} \mathrm{NMR}(101 \mathrm{MHz}$, DMSO) $\delta 178.48,177.94,159.47,152.08,144.56,136.99,135.16,135.02,134.99,131.98,131.06,127.69$, $127.18,127.04,119.70,115.16,20.46 . \mathrm{MS}(\mathrm{ESI})$ for $\left(\mathrm{C}_{17} \mathrm{H}_{10} \mathrm{CINO}_{5}[\mathrm{M}-]\right)$ : 343.0. Found 343.0.

2-Bromo-3-(3-methyl-4-nitrophenoxy)naphthalene-1,4-dione 3i. Yellow solid, yield $32 \%, \mathrm{mp} 174-176^{\circ} \mathrm{C} .{ }^{1} \mathrm{H}$

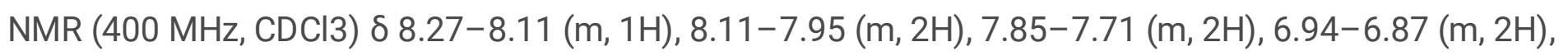
$2.59(\mathrm{~s}, 3 \mathrm{H}) .{ }^{13} \mathrm{C}$ NMR $(101 \mathrm{MHz}, \mathrm{CDCl} 3) \delta 178.00,176.87,158.86,154.99,144.74,137.29,134.89$, $134.69,131.08,130.38,129.07,127.92,127.49,127.46,119.90,114.41,21.27$. MS (ESI) for $\left(\mathrm{C}_{17} \mathrm{H}_{10} \mathrm{BrNO}_{5}\right.$ [M-]): 386.9. Found 387.0.

\section{Trypanosomicidal effect}

T. cruzi NINOA and INC-5 strain epimastigotes were grown at $28^{\circ} \mathrm{C}$ in an axenic medium (BHI), as previously described [22], and complemented with $5 \%$ foetal bovine serum. Epimastigotes from a 10-dayold culture (stationary phase) were inoculated into $50 \mathrm{~mL}$ of fresh culture medium to reach an initial concentration of $1 \times 10^{6}$. Cell growth was monitored by measuring culture absorbance of the culture at $600 \mathrm{~nm}$ in an ELISA Epoch reader (Epoch 2 Microplate Spectrophotometer (BioTek Instruments, Inc., Winooski, VT, USA) every day. Before inoculation, the media was supplemented with a given amount of the drug from a stock solution in DMSO $(25 \mathrm{mM})$. The final DMSO concentration in the culture medium never exceeded $0.4 \%$ and the control was run in the presence of $0.4 \%$ DMSO and in the absence of drugs. The percentage of growth inhibition (\% GI) and half-maximal inhibitory concentration values $\left(\mathrm{IC}_{50}\right)$, and parasite growth were followed in the absence (control), and in the presence, of a range of concentrations of the corresponding drug. On day 5 , the absorbance of the culture was measured and related to the control. The $\mathrm{IC}_{50}$ value was determined as the concentration of drug needed to reduce the absorbance ratio by $50 \%$. The experiments of each compound were carried out in triplicate; Bzn was used as a reference compound.

Ex vivo evaluation of INC-5 and NINOA strain trypomastigotes 
CD1 mice, 6 to 8 weeks old, were peritoneally infected with bloodstream trypomastigotes of the INC-5 and NINOA strains, respectively. After 4 to 6 weeks, at the maximum peak of parasitaemia, the parasitized blood was obtained by cardiac puncture using sodium heparin as an anticoagulant. Blood was adjusted to $1 \times 10^{6}$ trypomastigotes/mL. In a 96-well plate, $90 \mu \mathrm{l}$ of infected blood and $10 \mu \mathrm{l}$ of $1,4-$ naphthoquinone derivatives or reference drug dilutions were deposited for a final volume of $100 \mu \mathrm{l}$ per well. Each evaluation was carried out in triplicate. The compounds with the best $\mathrm{IC}_{50}$ in the epimastigotes of each strain were evaluated in trypomastigotes of both strains at $20 \mu \mathrm{M}, 10 \mu \mathrm{M}$ and $5 \mu \mathrm{M}$. The reference drug benznidazole was used as a positive lysis control and wells with untreated blood trypomastigotes were used as a negative lysis control; the microplates were incubated at $4^{\circ} \mathrm{C}$ for $24 \mathrm{~h}$. Subsequently, mobile trypomastigotes were quantified using the Brener-Pizzi method, for this, $5 \mu \mathrm{L}$ of blood was deposited between a slide and a $13 \times 13$ coverslip. The trypomastigotes were counted in 15 microscope fields in an optical microscope with 40x magnification. The percentage of lysis of each treatment was calculated by comparing the viable trypomastigotes with the negative control [16]. The $\mathrm{LC}_{50}$ was determined by linear regression. The experiments were carried out in accordance with the recommendations and approval of the local Ethics and Research Committee (Approval number: ENCB / CEI / 078/2020).

\section{Cytotoxicity assays}

A 96-well plate was seeded with 50000 cells/well with RPMI medium and $2 \%$ foetal bovine serum and incubated for $24 \mathrm{~h}$ at $37^{\circ} \mathrm{C}$. The compound from stock was dissolved in DMSO for subsequent serial dilutions with PBS until a concentration in the plate that did not exceed $1 \%$ of DMSO was reached. After $24 \mathrm{~h}$, the culture medium was removed from the plate and fresh culture medium was added together with the compounds reaching a final volume of $100 \mu$ per well. The plate was then incubated for $24 \mathrm{~h}$ at $37^{\circ} \mathrm{C}$ in $5 \% \mathrm{CO}_{2}$ where the following controls were added: cells with the medium as a positive control; cells without culture medium as a negative control; and last, the reference drug, Bzn at a concentration of 20 $\mu \mathrm{M}$.

After $24 \mathrm{~h}$ of incubation, the cell morphology was observed with a microscope and the MTT viability assay was performed. The culture medium was removed and the MTT solution was prepared and later added to the cells; it was incubated for $1 \mathrm{~h}$ and the absorbance was read at $570 \mathrm{~nm}$. The following formula was used to obtain the percentage: $\%$ cytotoxicity $=(100$-(mean number of cells with treatment/cells without treatment) *100) [23].

\section{Pharmacophore}

A flexible alignment strategy was used, consisting of the overlap of 3D structures, and minimizing the relative distances between equivalent atoms, including the flexibility for all freedom degrees for all rotatable dihedral bonds. Polar-Charged-Hydrophobic (PCH) of the MOE program was used and evaluated over a centroid position (an averaged position of all atoms relates to the feature). Pharmacophoric features in this scheme are annotated as Aro (aromatic), hydrophobic (Hyd), acceptor hydrogen bonding (Acc), and capacity to bound to metallic centres $(\mathrm{ML})$. Afterward, databases were spotted in groups of 
high and low growth inhibition of parasites in epimastigotes or trypomastigotes of INC-5, NINOA, respectively. For each group, a pharmacophore was built, and all features present in a minimum of $60 \%$ of molecules were retained. Finally, all pharmacophores were compared.

\section{Results And Discussion Chemistry}

We synthesized new aryloxy-naphthoquinones by nucleophilic substitution reaction of phenols with halo or dihaloquinones in a basic medium at room temperature (Scheme 1) $[12,15,11]$. These aryloxynaphthoquinones were obtained from low to moderate yields (23-67\%). The chemical structures of the compounds 3a-i were established based on their spectral properties (IR, ${ }^{1} \mathrm{H}-\mathrm{NMR},{ }^{13} \mathrm{C}-\mathrm{NMR}$ and MS). The chemical structures and the yield for the synthesis of $3 a-i$ are shown in the Table 1. 
Table 1

Yields for synthesis of aryloxy-naphthoquinone derivatives

Compound Yield (\%)

Biology

Trypanosomicidal effect against on the epimastigote form 
First, a screening assay was performed on the INC- 5 and NINOA strains at a fixed concentration of $10 \mu \mathrm{M}$ to determine the trypanosomicidal effect against epimastigote cultures. The results indicated that all compounds had a percentage of growth inhibition (\% GI) in both strains greater than $70 \%$. Considering these results, a dose-dependent assay was carried out using different concentrations $(5 \mu \mathrm{M}, 2.5 \mu \mathrm{M}, 1.25$ $\mu \mathrm{M}, 0.625 \mu \mathrm{M}$ to determine the half-maximal inhibitory concentration $\left(\mathrm{IC}_{50}\right)$ in each strain (Table 2).

All the naphthoquinone derivatives showed greater potency than the reference drug Bzn on the INC-5 and NINOA epimastigotes strains. Interestingly, compounds $3 i$ and $3 \mathbf{c}$ were 1000 and 100 -fold more potent than Bzn against the INC-5 strain, respectively. From the chemical point of view, the most active compounds in both strains were $3 \mathbf{i}\left(\mathrm{IC}_{50}=40 \mathrm{nM}\right.$ on INC-5) and $3 f\left(I C_{50}=1.14 \mu \mathrm{M}\right.$ on INC-5). These compounds present a bromine atom at 3-position on the naphthoquinone scaffold. In general, in the INC5 strain, compounds that have a halogen at 3-position, had greater potency than those did not present a substitution in this position (3a and $\mathbf{3 d}$ ). The same observation was noticed in the NINOA strain except for compound 3d, which presented a potency comparable to the derivatives that have halogens at 3position. On the other hand, the position of the nitro, chloro, or methyl group on the aryloxy moiety does not seem to significantly affect the activity in either strain. However, the halogen attached at 3-position on the naphthoquinone core seems to influence the potency over epimastigotes, since the molecules with a bromine atom were more potent than those with a chlorine atom, and those without substitution in this position are the least active. Therefore, the order of activity follows the pattern: $\mathrm{Br}>\mathrm{Cl}>\mathrm{H}$. 
Table 2

Effect of 3a-i and Bzn on culture growth of epimastigote and trypomastigote forms of T. cruzi

\begin{tabular}{|c|c|c|c|c|}
\hline \multirow[t]{2}{*}{ Compound } & \multicolumn{2}{|c|}{ Epimastigote form } & \multicolumn{2}{|c|}{ Trypomastigote form } \\
\hline & $\begin{array}{l}\text { INC-5 IC } 50 \\
(\mu \mathrm{M})^{\mathrm{a}}\end{array}$ & NINOA IC $_{50}(\mu \mathrm{M})$ & $\begin{array}{l}\text { INC-5 LC } 50 \\
(\mu \mathrm{M})\end{array}$ & NINOA LC ${ }_{50}(\mu \mathrm{M})$ \\
\hline $3 a$ & $0.73 \pm 0.04$ & $4.86 \pm 0.07$ & $N T^{b}$ & NT \\
\hline $3 b$ & $0.51 \pm 0.02$ & $3.06 \pm 0.05$ & NT & 9.38 \\
\hline $3 c$ & $0.41 \pm 0.01$ & $1.70 \pm 0.42$ & 24.74 & 20.35 \\
\hline $3 d$ & $1.63 \pm 0.02$ & $2.26 \pm 0.07$ & NT & NT \\
\hline $3 e$ & $0.66 \pm 0.01$ & $2.15 \pm 0.83$ & NT & NT \\
\hline $3 f$ & $0.88 \pm 0.03$ & $1.14 \pm 0.03$ & 24.76 & 20.01 \\
\hline $3 \mathbf{g}$ & $0.64 \pm 0.02$ & $1.41 \pm 0.05$ & 39.11 & 9.75 \\
\hline $3 \mathrm{~h}$ & $0.67 \pm 0.02$ & $1.45 \pm 0.03$ & NT & NT \\
\hline $3 \mathbf{i}$ & $0.04 \pm 0.02$ & $1.84 \pm 0.18$ & 27.50 & 35.36 \\
\hline Bzn & $42.3 \pm 5.8$ & $8.21 \pm 1.8$ & 46.67 & 40.67 \\
\hline \multicolumn{5}{|c|}{${ }^{\mathrm{a}}$ The results are means of three independent experiments } \\
\hline${ }^{\mathrm{b}} \mathrm{NT}=$ not te & & & & \\
\hline
\end{tabular}

The half-maximal lytic concentration $\left(\mathrm{LC}_{50}\right)$ in the trypomastigote form of both strains was measured for the compounds showed the lowest $\mathrm{IC}_{50}$ values. The best results were obtained in the NINOA strain with $\mathrm{LC}_{50}$ values of 9.38 and $9.75 \mu \mathrm{M}$ for compounds $\mathbf{3 b}$ and $\mathbf{3 g}$, respectively (Table 2 ). These compounds were four-fold more active than Bzn $\left(\mathrm{LC}_{50}=40.67 \mu \mathrm{M}\right)$. On the other hand, in the INC-5 strain, two compounds, $3 \mathbf{c}$ and $\mathbf{3 g}$ showed approximately two-fold greater potency than Bzn $\left(\mathrm{LC}_{50}=46.67 \mu \mathrm{M}\right)$. However, it was not possible to establish a structure-activity relationship in trypomastigotes because the assayed compounds were limited in number It is remarkable that in NINOA, the most active compounds were those with a chlorine atom at 3-position on the naphthoquinone core.

The important results are obtained from these strains. The trypomastigote is the infective flagellated form of the parasite in the blood. This form is responsible for the acute and chronic stages of Chagas disease in mammalian hosts [16]. Epimastigotes were used as a primary screening because their replication is extracellular, and they are easy to handle and maintain in the laboratory [17]. 


\section{Cytotoxicity in murine macrophages}

The cytotoxicity of the most promising compounds $\mathbf{3 b}, \mathbf{3 c}, \mathbf{3 f}, \mathbf{3 g}$ and $\mathbf{3 i}$ was determined on the murine macrophage $\mathbf{J 7 7 4}$ cell line (Table 3). In general, the five derivatives had greater selectivity for the epimastigote form of both strains, with $3 i$ being the compound with the highest selectivity index ( $\mathrm{SI}=$ 320). Moreover, it is important to point out the high selectivity of compound $\mathbf{3 b}$ against the NINOA strain in trypomastigotes. The SI for $\mathbf{3 b}$ was comparable with Bzn but with a better $\mathrm{LC}_{50}$ on this strain than this reference drug.

Table 3

Selective index (SI) values calculated for the most promising compounds

\begin{tabular}{|c|c|c|c|c|c|}
\hline Compound & $\begin{array}{l}J_{774} \mathrm{IC}_{50} \\
(\mu \mathrm{M})^{\mathrm{a}}\end{array}$ & INC-5(Epi) SI & $\begin{array}{l}\text { NINOA (Epi) } \\
\text { SI }\end{array}$ & $\begin{array}{l}\text { INC-5(Tryp) } \\
\text { SI }\end{array}$ & NINOA(Tryp) SI \\
\hline $3 b$ & 117 & 229 & 38.2 & $N T^{\mathrm{c}}$ & 12.5 \\
\hline $3 c$ & 9.4 & 23 & 5.5 & 0.4 & 0.5 \\
\hline $3 f$ & 13.6 & 16 & 12.0 & 0.5 & 0.7 \\
\hline $3 g$ & 11.9 & 19 & 8.4 & 0.3 & 1.2 \\
\hline $3 \mathbf{i}$ & 12.8 & 320 & 6.9 & 0.5 & 0.4 \\
\hline Bzn & 352 & 8.3 & 42.8 & 7.5 & 8.7 \\
\hline \multicolumn{6}{|c|}{ 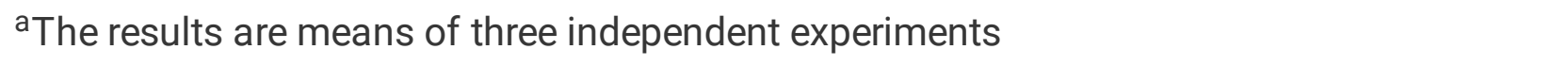 } \\
\hline \multicolumn{6}{|c|}{ bSI value $=\mathrm{IC}_{50}$ values on $\mathrm{J} 774$ cells $/ \mathrm{IC}_{50}$ or $\mathrm{LC}_{50} \mathrm{~T}$. cruzi } \\
\hline${ }^{\mathrm{C}} \mathrm{NT}=$ not tes & & & & & \\
\hline
\end{tabular}

\section{Pharmacophoric elucidation}

Compounds were aligned by a flexible alignment technique. This technique overlaps 3D structures minimizing the relative distances between equivalent atoms (in each molecule), including flexibility that allows all degrees of freedom in the rotatable angles, covering all possible dihedral angles. The pharmacophoric model was built using the Polar-Charged-Hydrophobic $(\mathrm{PCH})$ scheme in the MOE program [18]. The model was built with all features present in at least $60 \%$ of aligned molecules, resulting in the selection of the following features: Aromatic rings (Aro); Hydrophobic centre (Hyd); Hydrogen bond acceptor capacity (Acc); Metal ligation site (ML), and a combination of these. Some combinations could be defined (Acc\&ML). Considering that there are more $\mathrm{IC}_{50}$ values for the epimastigote form in both strains, a pharmacophoric model was carried out.

Pharmacophoric models for INC-5 epimastigote T. cruzi growth inhibitors 
The molecules were classified according to their trypanosomicidal (INC-5 epimastigotes) high or low growth inhibition (Fig. 2); their differential features were also detected. The main difference observed between both groups was sites bound to metals (meta-position, red spheres) non-favouring bioactivity. In this place, a nitro group at meta-position on aryloxy moiety favoured the desired bioactivity. This change affected the electronic density of the aromatic ring sustaining this group because of the high electronegativity of nitrogen and oxygen atoms of the nitro substituent.

\section{Pharmacophoric models of NINOA epimastigotes T. cruzi growth inhibitors}

The molecules were classified according to their trypanosomicidal (NINOA epimastigotes) high or low growth inhibition (Fig. 3); their differential features were also detected. In this case, bioactivity (NINOA T. cruzi epimastigotes growth inhibition) is favoured with the presence of acceptor groups of metallic atoms at para position on the phenoxy group (cyan spheres) and non-favoured when these features are placed at meta-position (red spheres).

\section{Physicochemical properties}

Drug-likeness properties such as the pharmacokinetic (ADME) and pharmacodynamic (e.g., toxicological) profiles are important during the process of discovery and development process of a drug. These properties are shown the optimization of a leading compound to a successful candidate for pre-clinical stages [19].

ADMET properties are important to determine some chemical descriptors such as the polar surface area (PSA) and the molecular weight (MW) of molecules, which are useful to determine the oral absorption of drugs. Small and hydrophilic molecules are undergoing rapid renal clearance, while large and hydrophobic compounds are undergoing extensive hepatic metabolism and poor absorption [20]. Therefore, finding a suitable hydrophilic-hydrophobic drug balance is a great challenge for medicinal chemists. Thus, to evaluate these properties and predict good oral bioavailability, two sets of rules, Lipinski and Veber, should be followed to make a good prediction [21, 20].

Lipinski's rule of five states that an orally bioavailable molecule should not violate the following criteria: $\leq 5$ hydrogen bond donors (HBD); $\leq 10$ hydrogen bond acceptors (HBA); a $\mathrm{MW}<500$, and a log P-value $<$ 5. On the other hand, Veber et al. described the role of PSA and the number of rotatable bonds as criteria to estimate oral bioavailability. Veber's rule states that the compound to be orally bioavailable, it should have either a PSA $\leq 140 \AA$ and $\leq 10$ rotatable bonds (NRB) or $\leq 12$ HBD and HBA in total and $\leq 10$ rotatable bonds. As shown in Table 4, compounds 3a-i achieved the Drug-likeness criteria described by Lipinski and Veber; therefore, they are expected to have good oral bioavailability. 
Table 4

Molecular properties of compounds 3a-i

\begin{tabular}{|lllllll|}
\hline Compound & MW (Da) & HBA & HBD & MiLogP & TPSA (A ${ }^{2}$ ) & NRB \\
\hline Desirable value & $\leq 500$ & $\leq 10$ & $\leq 5$ & $\leq 5$ & $\leq 140$ & $\leq 10$ \\
\hline 3a & 309.28 & 6 & 0 & 3.69 & 89.20 & 3 \\
\hline 3b & 343.72 & 6 & 0 & 4.29 & 89.20 & 3 \\
\hline 3c & 388.17 & 6 & 0 & 4.42 & 89.20 & 3 \\
\hline 3d & 329.69 & 6 & 0 & 3.91 & 89.20 & 3 \\
\hline 3e & 364.14 & 6 & 0 & 4.52 & 89.20 & 3 \\
\hline 3f & 408.59 & 6 & 0 & 4.65 & 89.20 & 3 \\
\hline 3g & 329.69 & 6 & 0 & 3.91 & 89.20 & 3 \\
\hline 3h & 343.72 & 6 & 0 & 4.29 & 89.20 & 3 \\
\hline 3i & 388.17 & 6 & 0 & 4.42 & 89.20 & 3 \\
\hline \begin{tabular}{l} 
MW: Molecular weight; HBA: Number of hydrogen bond acceptors; HBD: Number of hydrogen bond \\
donors; MiLogP: Log Palue predicted by Molinspiration (www.https://www.molinspiration.com); \\
\hline TPSA: Topological polar surface; NRB: number of rotatable bonds.
\end{tabular} \\
\hline
\end{tabular}

\section{Conclusions}

In this study, a set of nine aryloxy-naphthoquinones were synthesised and evaluated in vitro and ex vivo against the epimastigote and trypomastigote forms in two Mexican T. cruzi strains. The trypanosomicidal activity of these compounds against both forms and were better than the reference drug, benznidazole (Bzn). The most promising naphthoquinone derivative is compound $\mathbf{3 b}$ due to its highest trypanosomicidal activity against epimastigotes (INC-5 and NINOA strains) and trypomastigote (NINOA strain) and SI values. From the theoretical studies, important features from pharmacophoric models were identified to develop the more active naphthoquinone derivatives. Predictions about their ADME properties indicated that these aryloxy-naphthoquinones would have good bioavailability.

\section{Declarations}

\section{Acknowledgements}

C.O.S. thanks to DIPOG project $N^{\circ} 3913-406-81$ and C. E.-B. gratefully acknowledges the financial support from FONDECYT (Research Grant No. 1180292).

\section{Conflict of interest}

The authors declare that there is no conflict of interest. 


\section{References}

1. Organization WH. Available online: https://www.who.int/neglected_diseases/diseases/en/. 2020

2. Zuma AA, de Souza W (2021) Chagas Disease Chemotherapy: What Do We Know So Far? Curr Pharm Des. doi:10.2174/1381612827666210216152654

3. Altcheh J, Moscatelli G, Moroni S, Garcia-Bournissen F, Freilij H (2011) Adverse Events After the Use of Benznidazole in Infants and Children With Chagas Disease. Pediatrics 127(1):e212-e218. doi:10.1542/peds.2010-1172

4. Apt BW, Heitmann GI, Jercic LM, Jotre ML, Munoz CDVP, Noemi HI et al (2008) [Guidelines for chagas disease: Part IV. Chagas disease in immune compromised patients]. Rev Chilena Infectol 25(4):289292. doi:/S0716-10182008000400008

5. Scarim CB, Chin CM (2019) Current Approaches to Drug Discovery for Chagas Disease: Methodological Advances. Comb Chem High Throughput Screen 22(8):509-520. doi:10.2174/1386207322666191010144111

6. Villalta F, Rachakonda G (2019) Advances in preclinical approaches to Chagas disease drug discovery. Expert Opin Drug Discov 14(11):1161-1174. doi:10.1080/17460441.2019.1652593

7. Boveris A, Docampo R, Turrens JF, Stoppani AO (1978) Effect of beta-lapachone on superoxide anion and hydrogen peroxide production in Trypanosoma cruzi. Bioch J 175(2):431-439. doi:10.1042/bj1750431

8. Diogo EBT, Dias GG, Rodrigues BL, Guimarães TT, Valença WO, Camara CA et al (2013) Synthesis and anti-Trypanosoma cruzi activity of naphthoquinone-containing triazoles: electrochemical studies on the effects of the quinoidal moiety. Bioorg Med Chem 21(21):6337-6348. doi:10.1016/j.bmc.2013.08.055

9. Bolognesi ML, Lizzi F, Perozzo R, Brun R, Cavalli A (2008) Synthesis of a small library of 2-phenoxy1,4-naphthoquinone and 2-phenoxy-1,4-anthraquinone derivatives bearing anti-trypanosomal and anti-leishmanial activity. Bioorg Med Chem Lett 18(7):2272-2276. doi:10.1016/j.bmcl.2008.03.009

10. Tapia RA, Salas CO, Vázquez K, Espinosa-Bustos C, Soto-Delgado J, Varela J et al (2014) Synthesis and biological characterization of new aryloxyindole-4,9-diones as potent trypanosomicidal agents. Bioorg Med Chem Lett 24(16):3919-3922. doi:https://doi.org/10.1016/j.bmcl.2014.06.044

11. Vázquez K, Espinosa-Bustos C, Soto-Delgado J, Tapia RA, Varela J, Birriel E et al (2015) New aryloxyquinone derivatives as potential anti-Chagasic agents: synthesis, trypanosomicidal activity, electrochemical properties, pharmacophore elucidation and 3D-QSAR analysis. RSC Adv 5(80):65153-65166. doi:10.1039/C5RA10122K

12. Espinosa-Bustos C, Vázquez K, Varela J, Cerecetto H, Paulino M, Segura R et al (2020) New aryloxyquinone derivatives with promising activity on Trypanosoma cruzi. Arch Pharm 353(1):1900213. doi:https://doi.org/10.1002/ardp.201900213

13. Jarvis LM (2018) the year in new drugs: fda approvals hit a 20-year high in 2017, with cancer and rare-disease drugs dominating the list of new medicines. Chem Eng News 96(4):25-30 
14. González A, Becerra N, Kashif M, González M, Cerecetto H, Aguilera E et al. In vitro and in silico evaluations of new aryloxy-1,4-naphthoquinones as anti-Trypanosoma cruzi agents. Med Chem Res. 2020;29(4):665 - 74. doi:10.1007/s00044-020-02512-9

15. Tapia RA, Salas C, Morello A, Maya JD, Toro-Labbe A (2004) Synthesis of dihydronaphthofurandiones and dihydrofuroquinolinediones with trypanocidal activity and analysis of their stereoelectronic properties. Bioorg Med Chem 12(9):2451-2458. doi:10.1016/j.bmc.2004.01.046

16. Chacón-Vargas KF, Nogueda-Torres B, Sánchez-Torres LE, Suarez-Contreras E, Villalobos-Rocha JC, Torres-Martinez Y et al. Trypanocidal Activity of Quinoxaline 1,4 Di-N-oxide Derivatives as Trypanothione Reductase Inhibitors. Molecules. 2017;22(2). doi:10.3390/molecules22020220

17. Martin-Escolano R, Martin-Escolano J, Ballesteros-Garrido R, Cirauqui N, Abarca B, Rosales MJ et al (2020) Repositioning of leishmanicidal [1,2,3]Triazolo[1,5-a]pyridinium salts for Chagas disease treatment: Trypanosoma cruzi cell death involving mitochondrial membrane depolarisation and FeSOD inhibition. Parasitol Res 119(9):2943-2954. doi:10.1007/s00436-020-06779-0

18. MOE (2013) Molecular Operating Environment 08, Chemical Computing. Group, Inc., Montreal

19. Meanwell NA (2011) Improving drug candidates by design: a focus on physicochemical properties as a means of improving compound disposition and safety. Chem Res Toxicol 24(9):1420-1456. doi:10.1021/tx200211v

20. Lipinski CA, Lombardo F, Dominy BW, Feeney PJ (2001) Experimental and computational approaches to estimate solubility and permeability in drug discovery and development settings. Adv Drug Deliv Rev 46(1-3):3-26. doi:10.1016/s0169-409x(00)00129-0

21. Veber DF, Johnson SR, Cheng HY, Smith BR, Ward KW, Kopple KD (2002) Molecular properties that influence the oral bioavailability of drug candidates. J Med Chem 45(12):2615-2623. doi:10.1021/jm020017n

22. Alvarez G, Varela J, Marquez P, Gabay M, Arias Rivas CE, Cuchilla K et al (2014) Optimization of antitrypanosomatid agents: identification of nonmutagenic drug candidates with in vivo activity. $\mathrm{J}$ Med Chem 57(10):3984-3999. doi:10.1021/jm500018m

23. Faundez M, Pino L, Letelier P, Ortiz C, Lopez R, Seguel C et al (2005) Buthionine sulfoximine increases the toxicity of nifurtimox and benznidazole to Trypanosoma cruzi. Antimicrob Agents Chemother 49(1):126-130. doi:10.1128/AAC.49.1.126-130.2005

\section{Figures}


$\overbrace{O}^{O H}$<smiles>CC1(C)CCC2=C(O1)C(=O)c1ccccc1C2=O</smiles>

II<smiles>O=C1C=C(Oc2ccccc2)C(=O)c2ccccc21</smiles>

III<smiles>CCOC(=O)c1cc2c(n1CC)C(=O)C(Oc1ccccc1)=CC2=O</smiles>

IV<smiles>O=C1C=C(Oc2cccc([N+](=O)[O-])c2)C(=O)c2ccccc21</smiles><smiles>Cc1ccc(OC2=CC(=O)c3ccccc3C2=O)cc1[N+](=O)[O-]</smiles>

VI

\section{Figure 1}

Chemical structures of lapachol (I), a-lapachone (II) and aryloxy-quinones (III-VI) with trypanosomicidal activity, and new aryloxy-naphthoquinones studied in this work

(a)
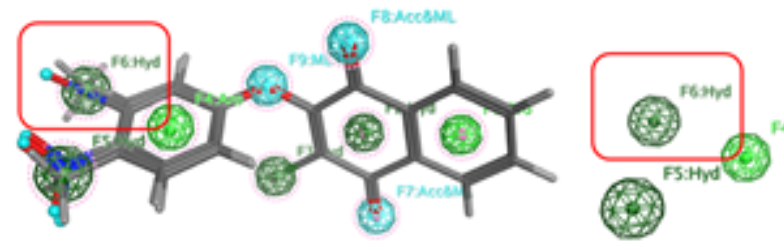

$6{ }^{n}$

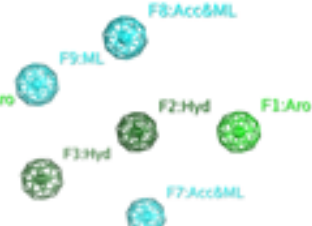

(b)
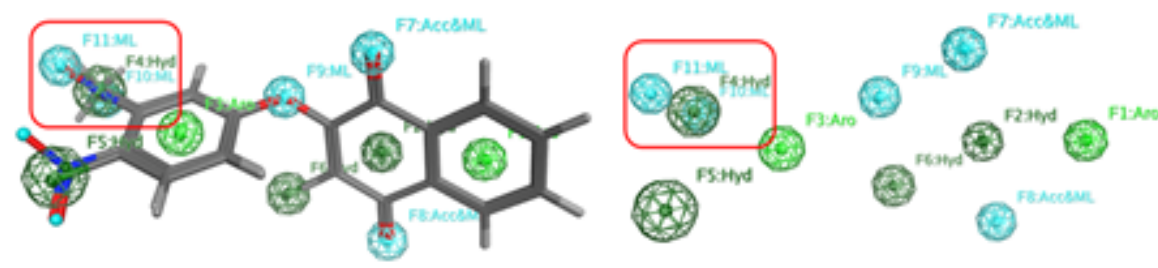

(c)

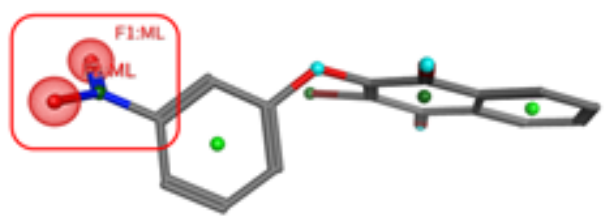

Figure 2

Pharmacophores of molecules with high (a) or low (b) bioactivity and observed differences (c) between both models 
(a)
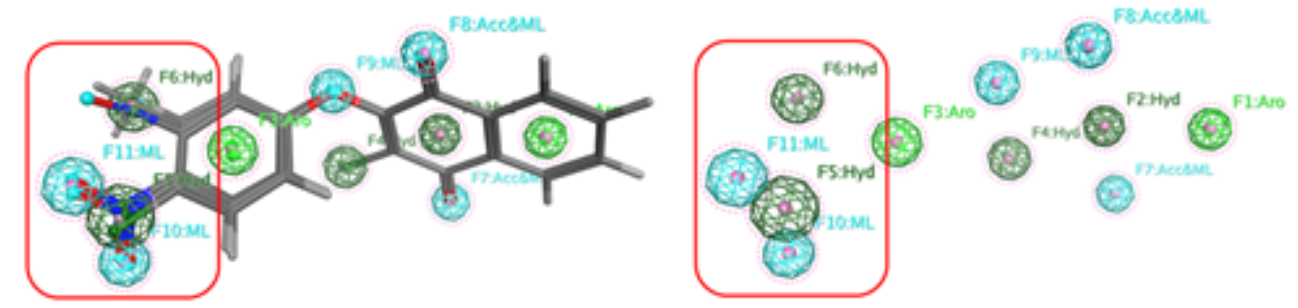

(b)
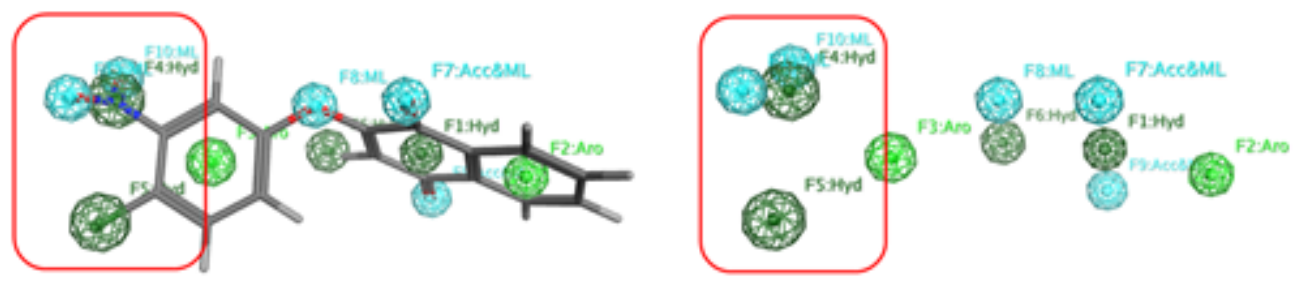

(c)
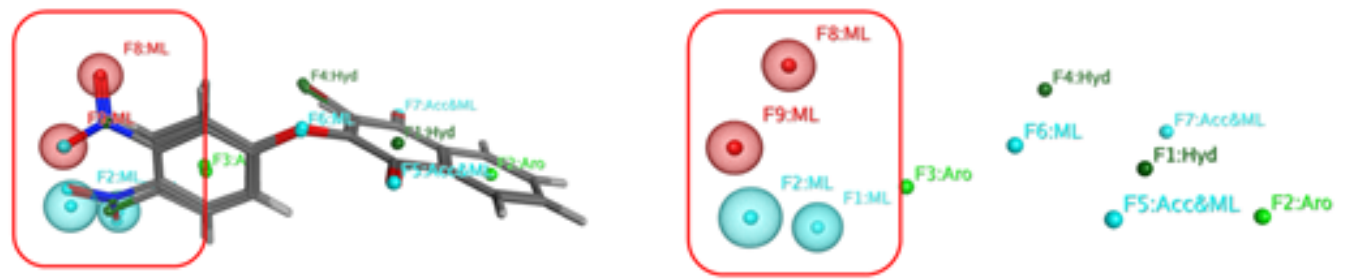

\section{Figure 3}

Pharmacophores of molecules with high (a) or low (b) bioactivity (NINOA T. cruzi epimastigotes) and observed differences (c) between both models

\section{Supplementary Files}

This is a list of supplementary files associated with this preprint. Click to download.

- SupportinginformationMCR2021.docx

- floatimage1.png

- Scheme01.png 